\title{
硬膜動静脈瘻の血管内治療における合併症の現状と対策
}

\author{
桑山 直也, 久保 道也, 堀 恵美子 \\ 津村貢太朗，栄楽 直人，遠藤 俊郎
}

\section{Dural Arteriovenous Fistulas: Complications of Endovascular Treatment}

Naoya Kuwayama, M.D., Michiya Kubo, M.D., Emiko Hori, M.D., Koutaro Tsumura, M.D., Naoto Eiraku, M.D., and Shunro Endo, M.D.

Department of Neurosurgery, University of Toyama, Toyama, Japan

Summary: To evaluate complications and their prevention in endovascular treatment of dural arteriovenous fistulas (AVFs), we analyze the medical records of 105 patients (47 men 58 women, mean age of 64.2 years) treated with endovascular procedures from 1990 to 2003 in our clinic. Dural AVF was located at the cavernous sinus in 43 patients, transverse-sigmoid sinus in 43 , and other regions in 19. There were 201 procedures, including 97 transarterial embolizations (TAE), 84 transvenous embolizations (TVE), 17 surgical TVEs, and 3 sinoplasties.

Twelve complications were recorded in 10 patients ( 3 cavernous sinus, 5 transverse-sigmoid sinus, and 2 craniocervical junction lesions). The complications were divided into 4 categories: wrong strategy ( 1 case), venous thrombosis ( 2 cases), procedural error ( 7 cases), and general condition (1 case; pulmonary embolism).

One of the superficial middle cerebral veins was obliterated after coiling of the cavernous sinus in 1 patient, resulting in a mild transient hemiparesis (wrong strategy). The syndrome of paradoxical worsening occurred in 1 patient with cavernous sinus dural AVF after TAE (venous thrombosis of the central retinal vein). One patient with sigmoid sinus dural AVF suffered long-lasting dizziness after TVE. Ipsilateral endolymphatic hydrops were observed and speculated to be a causative factor of the patient's dizziness (venous thrombosis of the inner ear). The procedural error included trigeminal nerve palsy due to excess coil packing ( 1 case in TVE), ischemic cranial neuropathy (3 cases in TAE), and migration of the embolic materials via the feeding arterial collateral network (3 cases in TAE).

Morbidity and mortality were $4.8 \%$ and $1.0 \%$, respectively. We discuss causes and preventive measures.

\footnotetext{
Key words:

- dural arteriovenous fistula

- endovascular treatment complication

- transarterial embolization

- transvenous embolization
}

Surg Cereb Stroke

(Jpn) 34: 91-95, 2006 


\section{はじめに}

硬膜動静脈瘻の治療成績は脳血管内治療の進歩とともに 飛躍的に向上した。治療戦略を練るためには本疾患の複雑 な血行動態を的確に把握することが重要であり，その結果 選択される手技は経動脈的塞栓術 (TAE), 経静脈的塞栓 術 (TVE), 外科手技や放射線療法との併用療法など, 状 況によりさまざまである。治療者の技量が求められる疾患 でもあり，起こりうるさまざまな合併症への対策も重要で ある．われわれはこれまでに血管内治療を施行した頭蓋内 および脊髄硬膜動静脈㾞症例の記録を調查し，治療により 生じた合併症について検討するとともに，その対策につい て考察した。

\section{対象・方法}

1990 年から 2003 年までに当教室で経験した 145 例の頭 蓋内および金髄硬膜動静脈瘻症例のうち，血管内治療を施
行した 105 例を対象とした。男性が 47 例，女性 58 例で， 年齢は 45 歳から 87 歳，平均 $64.2 \pm 9.6$ 歳であった。これら 105 例について, 発生部位, 治療手技, 治療結果, 治療合 併症，転帰を retrospectiveに分析した。合併症について はカテゴリー(治療戦略，治療手技，静脈血栓症，全身性） にわけて原因を分析した。また，転帰はGOS（Glasgow outcome scale)で評価した。

\section{結果}

105 例に対し 192 件，201 手技 (transarterial embolization (TAE)：97 手技, transvenous embolization (TVE) : 84 手技, surgical $\mathrm{TVE}^{4)}$ 5) $: 17$ 手技，静脈洞拡張術： 3 手 技)の血管内治療を施行した。

部位別では海綿静脈洞部が 43 症例 (69 件，TAE：15 手 技，TVE: 52 手技， surgical TVE: 3 手技), 横 - S 状静脈 洞部が 43 症例 (89 件，TAE: 51 手技，TVE: 31 手技，surgical TVE: 12 手技, 静脈洞拡張術 : 3 手技), その他の部

Table 1 Number of cases, sessions, and procedures

\begin{tabular}{cccccccc}
\hline \multirow{2}{*}{ Location } & \multirow{2}{*}{ Case } & \multirow{2}{*}{ Session } & \multicolumn{7}{c}{ Procedure } \\
\cline { 4 - 7 } & & & TAE & TVE & sTVE & PTS & total \\
\hline CS & 43 & 69 & $15(1)$ & $52(2)$ & 3 & 0 & 70 \\
TSS & 43 & 89 & $51(5)$ & $31(1)$ & 12 & 3 & 97 \\
others & 19 & 34 & $31(3)$ & 1 & 2 & 0 & 34 \\
\hline total & 105 & 192 & $97(9)$ & $84(3)$ & 17 & 3 & 201 \\
\hline
\end{tabular}

CS: cavernous sinus, PTS: percutaneous transluminal sinoplasty, sTVE: surgical transvenous embolization TAE: transarterial embolization, TSS: transverse-sigmoid sinus, TVE: transvenous embolization

( ) number of complications

Table 2 Complications, causes, and outcome

\begin{tabular}{|c|c|c|c|c|c|c|c|c|c|}
\hline Case & Age & Sex & Location & Procedure & Material & Complication & Causes of complication & Category & GOS \\
\hline 1 & 57 & $\mathrm{~F}$ & CS & TVE & FPC & SMCV occlusion & failed strategy & strategy & GR \\
\hline 2 & 72 & $\mathrm{~F}$ & CS & TAE & FPC & IOP elevation, visual impairment & thrombosis of the SOV & venous thrombosis & MD \\
\hline 3 & 55 & $M$ & CS & TVE & DC & trigeminal nerve impairment & excessive packing & procedural & MD \\
\hline \multirow[t]{2}{*}{4} & 63 & $\mathrm{~F}$ & TSS & TAE & PVA & facial palsy & ischemic cranial neuropathy & procedural & MD \\
\hline & & & & TAE & PVA & visual impairment & migration via the dangerous anastomosis & procedural & MD \\
\hline 5 & 65 & M & TSS & TAE & NBCA & lung embolism & venous thrombosis & general & D \\
\hline 6 & 63 & $M$ & TSS & TAE & NBCA & lower cranial nerve palsy & ischemic cranial neuropathy & procedural & GR \\
\hline 7 & 72 & $M$ & TSS & TAE & NBCA & lower cranial nerve palsy & ischemic cranial neuropathy & procedural & GR \\
\hline 8 & 52 & $\mathrm{~F}$ & TSS & TVE & DC & dizziness & venous thrombosis in the inner ear? & venous thrombosis & GR \\
\hline \multirow[t]{2}{*}{9} & 52 & $\mathrm{~F}$ & $\mathrm{CCJ}$ & TAE & NBCA & asymptomatic NBCA migration & migration via the dangerous anastomosis & procedural & \\
\hline & & & & TAE & & groin hematoma (contralateral) & previous puncture (diagnostic angiogram) & & PVS \\
\hline 10 & 65 & $M$ & $\mathrm{CCJ}$ & TAE & NBCA & NBCA migration & migration via the feeding arterial network & procedural & SD \\
\hline
\end{tabular}

CCJ: craniocervical junction, CS: cavernous sinus, DC: detachable coil, FPC: free platinum coil, GOS: Glasgow outcome scale, IOP: intraocular pressure, NBCA: n-buchyl-cyanoacrylate, PVA: polyvinyl alcohol, SOV: superior ophthalmic vein, SMCV: superficial middle cerebral vein, TAE: transarterial embolization, TSS: transverse-sigmoid sinus, TVE: transvenous embolization 


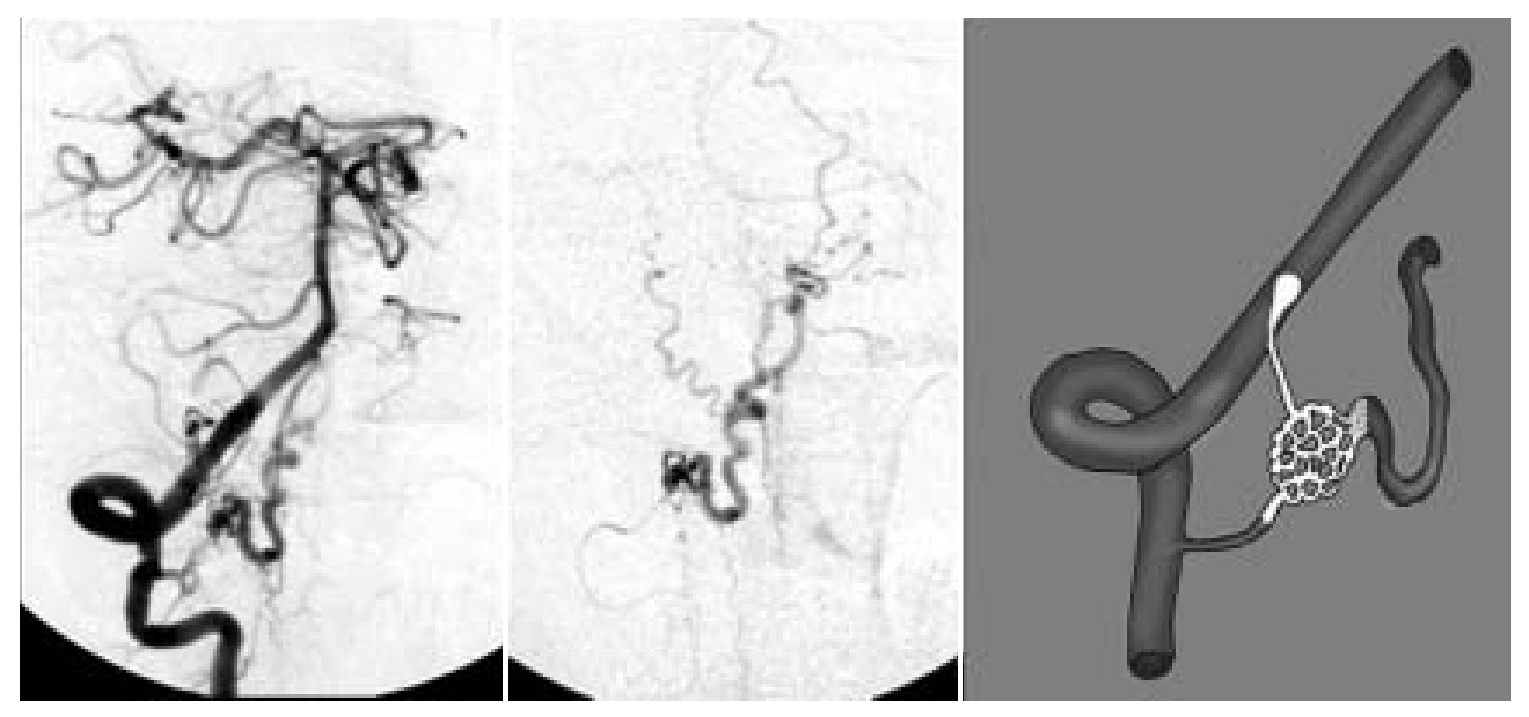

Fig. 1 left: right vertebral angiogram showing dural AV fistula at the craniocervical junction, center: superselective injection of the main feeding artery, right: schematic view of NBCA migration to the vertebral artery via the fistula and another feeding artery.

位としては上矢状静脈洞部 5 例, 頭蓋頸椎移行部 4 例, 頭 蓋円蓋部 3 例, テント部 1 例, 辺縁静脈洞部 1 例, 胸腰仙 部脊髄 5 例で, これら 19 例には 34 件 (TAE: 31 手技, TVE: 1 手技, surgical TVE: 2 手技) の血管内治療を施行

\section{した (Table 1).}

手技に伴う合併症は 10 例 12 件 (手技) で発生した。 その 内訳は下記に提示したごとく TAEで 9 件, TVEで 3 件で あった。

\section{合併症の詳細 (Table 2)}

1. 57 歳女性 : 海綿静脈洞部硬膜動静脈癭 (TVE).

右海綿静脈洞全体をコイルにて充填したところ, 右浅 中大脳静脈が閉塞し, 右側頭葉皮質下に小さな静脈性梗塞 をきたした. 軽い一過性の左麻痺が出現した. 本症例の右 浅中大脳静脈は術前から病側の海綿静脈洞に順行性に還流 しており, sphenopetrosal veinやsphenobasal veinなど 海綿静脈洞の迂回路(6) となるような静脈は発達していなか った。

2. 72 歳女性 : 海綿静脈洞部硬膜動静脈㿉 (TAE).

流入動脈をコイルにて閉塞後, 眼圧立進, 視力低下をき たした $\left(\right.$ paradoxical worsening $\left.{ }^{7)}\right)$. 視力低下は永続性であ つた.

3. 55 歳男性 : 海綿静脈洞部硬膜動静脈瘦 (TVE).

外転神経麻瘦を呈する動静脈瘻で, 2 回の TVEにより

同症状は消失したが, 術後, 同側三叉神経第一枝の永続性 知覚脱失をきたした.コイルの過剩塞栓が原因と推測され た.

4. 63 歳女性: 横 - S 状静脈洞部硬膜動静脈瘻 (TAE).
中硬膜動脈の petrosquamous branch (サイズ : 250-400 micron) で閉塞後, 同側の遅発性顔面 神経麻痺をきたした。別のセッションで浅側頭動脈を PVA particleにて閉塞後, 同側の視力低下をきたした。 眼科の精查にて網膜中心動脈への PVA particleの迷入が 確認された. 顔面神経麻疩, 視力低下はいずれも永続性で あった。

5. 65 歳男性 : 横 - S 状静脈洞部硬膜動静脈瘦 (TAE).

NBCA による流入動脈塞栓術を施行した。翌日と 7 日後 に肺塞栓症を合併し死亡した。

6. 63 歳男性 : 横 - S 状静脈洞部硬膜動静脈瘦 (TAE).

上行咽頭動脈を NBCA にて塞栓後, 一過性の軽い下位 脳神経麻痺 (嗄声, 嚥下障害)をきたした。

7. 72 歳男性 : 横 - S 状静脈洞部硬膜動静脈瘦 (TAE).

上行咽頭動脈を NBCA にて塞栓後, 一過性の軽い下位 脳神経麻痺 (嗄声, 曣下障害)をきたした。

8. 52 歳女性 : 横 - S 状静脈洞部硬膜動静脈瘦 (TVE). isolates sinusを呈する動静脈瘻に対し, 閉塞部にカテ ーテルを通すことにより経皮的経静脈的塞栓術を施行し た. 動静脈瘦は完全に閉塞したが, 術後, 動摇性のめまい 感が長期間残存した. 耳鼻科の精査により同側の内リンパ 水腫が指摘され, 静脈洞閉塞による内耳の静脈還流障害が 疑われた。

9. 52 歳女性 : 頭蓋頸椎移行部硬膜動静脈瘦 (TAE).

左後頭動脈に注入した NBCA が右椎骨動脈 (V2 部)に迷 入した. NBCAはV2 部に停留し, 拍動性に動摇していた ため，右椎骨動脈本幹を迷入部の中枢側でコイルにより閉 塞した. 無症状であった. 左大腿の穿刺部位を圧迫止血し 
Table 3 Complication and morbidity-mortality rate

\begin{tabular}{|c|c|c|c|c|c|}
\hline & Total number & Complications & Complication rate (\%) & Morbidity (\%) & Mortality (\%) \\
\hline total cases & 105 & 10 & 9.5 & 4.8 & 1.0 \\
\hline CS & 43 & 3 & 7.0 & 4.7 & 0 \\
\hline TS & 43 & 5 & 11.6 & 2.3 & 2.3 \\
\hline $\mathrm{CCJ}$ & 4 & 2 & 50.0 & 50.0 & 0 \\
\hline others & 19 & 0 & 0 & 0 & 0 \\
\hline total procedure & 201 & 12 & 6.0 & & \\
\hline TAE & 97 & 9 & 9.3 & & \\
\hline TVE & 84 & 3 & 3.6 & & \\
\hline others & 20 & 0 & 0 & & \\
\hline
\end{tabular}

CCJ: craniocervical junction, CS: cavernous sinus, TAE: transarterial embolization, TSS: transverse-sigmoid sinus, TVE: transvenous embolization

終了した。翌日，診断のために 3 日前に穿刺した右大腿部 より大量の出血 (穿刺部から後腹膜まで)をきたし，植物 状態となった。

10. 65 歳男性：頭蓋頸椎移行部硬膜動静脈瘦 (TAE).

右椎骨動脈 V3 部から出る流入動脈に注入した NBCA が, 動静脈瘦を介して V2 部から出る流入動脈に逆行性に 迷入し(Fig. 1), 右椎骨動脈および左後大脳動脈を閉塞し た. 永続性の下位脳神経麻疩と右片麻痺を後遺した。

\section{合併症のまとめ (Table 3)}

105 症例に対する 201 手技の血管内治療において, 10 例, 12 件の合併症が生じた。合併症発生率は全体で $9.5 \%$, morbidity は 5 例 (4.8\%), mortality は 1例 (1.0\%)であった.

部位別でみると, 海綿静脈洞部では全体で 3 例 $(7.0 \%)$ に 生じ, morbidityは 2 例 $(4.7 \%)$, mortality は 0 であった。 横・S 状静脈洞部では全体で 5 例 (11.6\%)に生じ, morbidity は 1 例 (2.3\%), mortality は 1 例 (2.3\%) であった。 その 他の部位で合併症が生じたのは頭蓋頸椎移行部で, 発生率 は50\%(2例), morbidityは50\%, mortalityは0であった。

手技別でみると全体では 201 件中 12 件 (6.0\%) で合併症 が生じた。TAEでは 97 件中, 9 件 $(9.3 \%)$ で発生し, その 中で塞栓物質が原因で生じたものは, 脳神経栄養枝の障害 が 3 件, 吻合枝を介する迷入が 3 件であった. TVEでは 84 件中 3 件 $(3.6 \%)$ に発生し， 2 件は静脈還流障害が原因， 1 件は過剩塞栓が原因と考えられた. surgical TVE, sinoplastyでは合併症は生じなかった.

\section{考察}

105 例, 201 件の血管内治療で生じた 10 症例 $/ 12$ 件の合 併症を原因別に分けると, 治療戦略に誤りがあったもの 1 件 (症例 1 /脳静脈閉塞), 流出静脈側の血栓症 2 件 (症例 2 / 眼窝内静脈血栓症, 症例 $8 /$ 内耳静脈?), 全身の要因 (症例
5/肺塞栓症)，および手技に関連したもの (症例 $3 ， 4 ， 6$, 7，9，10)であった.

戦略の誤りと判断された症例 1 の合併症は脈管解剖学の 熟知により回避しなければならない初歩的なものである.

流出静脈側の血栓症が原因となった 2 例はへパリンの持 続投与により回避できる可能性はあるが, 現時点ではコン センサスはない。症例 2 はいわゆる paradoxical worsening $^{7)}$ と報告されているもので, TAEにより動静脈㾇が閉 塞されたにもかかわらず，眼窩内の進行性静脈血栓症のた

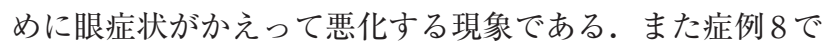
みられた内リンパ水腫は, 前庭静脈 (下錐体静脈洞に還流) あるいは内リンパ囊の静脈 ( $\mathrm{S}$ 状静脈洞に還流)の還流障害 が疑われる。

症例 5 の術後肺塞栓症は，血管内治療後を問わず安静臥 床を必要とする症例を扱う以上，なんとしても回避すべき 合併症である．1998年に本例を経験して以来，われわれ の施設では原則として血管内治療の術後 12 時間はへパリ ンを持続投与し，離床までは下肢に弾性包帯を装着してい る.

手技が原因となった 6 件の合併症は次の 3 群に分類され る；(1）TVEにおける過剩塞栓 (症例 3)，(2) TAEによ る脳神経栄養枝の虚血 (症例 $4,6,7$ ), (3) 流入動脈の吻 合枝を介した塞栓物質の迷入 (症例 $4,9,10$ ).

(1) 過剩塞栓による脳神経麻瘏は特に海綿静脈洞部で観 察され，塞栓中の圧の上昇や機械的圧迫などが原因 ${ }^{1)}$ と考 えられている. 血栓性の高い繊維付きプラチナコイルなど を適宜使用することにより過剩塞栓を防ぐことが可能と思 われる。

(2) 脳神経栄養枝の虚血および吻合枝からの迷入は特に 外頸動脈系の TAEに多い合併症で, 本報告でも小さな粒 子である PVA particle(サイズ：250-400 micron)や，液 体塞栓物質の NBCA で生じている。脳神経栄養枝の確認 
はリドカインテストである程度可能3) であるが, 治療中べ ッド上で臥床のままテストを行うため, われわれの経験で は特に下位脳神経の評価が甘くなりがちである。最近は内 視鏡を併用し，咽喉頭と声帯の動態を確実に評価できるよ う努力している.

（3）吻合枝を介した塞栓物質の迷入は catastrophic な合 併症を生ずるにもかかわらず，塞栓前にその存在を視認す ることが困難な場合が多く，最も危険で手ごわい現象であ る. 塞栓前の撮影も, リドカイン/アミタールテスト ${ }^{3)}$ も 予知に完全ではなく, 解剖を熟知し, 塞栓中にチャンネル が開くという前提を常に持ちながら動注を行うことが重要 と思われる．外頸動脈一内頸動脈間，および外頸動脈-椎骨 動脈間のいわゆる dangerous anastomosisに関する認識は 基本的かつ非常に重要である．われわれが経験した症例 4 の合併症は浅側頭動脈前頭枝と眼動脈との吻合を介し, PVA particleが網膜中心動脈を誤閉塞したものである. また動静脈瘻を介して複数の流入動脈間に形成される吻合 枝の存在も重要であり, 特に流入動脈の距離が短いものは 危険である。症例 10 (Fig. 1) は典型例で, 注入された $\mathrm{NBCA}$ が小さな瘦を瞬時に閉塞したのち，ごく短時間で 他の流入動脈を逆行し，術者が気づかないうちに椎骨動脈 本幹に迷入した。このように critical な動脈 (本例では椎骨 動脈) と動静脈瘻の距離が短い場合，逆行/迷入した NBCA を瞬時にとらえて注入を中止するのは非常に困難 で，もはや特殊な技能とさえいえる。一般的にはこのよう な症例は血管内治療の適応としないのが無難と考えられ る.

以上は筆者らが経験した合併症の分析と対策である。こ れら以外に念頭におくべき重要な合併症として，TVE術 中の脳内出血 ${ }^{2)}$ があげられる，TVEにより罹患静脈洞の 流出路を閉じる過程で次第に静脈洞圧が上昇し，uncal vein, petrosal veinなど脳静脈への逆行性還流が増加して 静脈性脳内出血をきたす catastrophic な合併症である. TVEで罹患静脈洞の流出路を閉塞していく場合，危険な ルートから順に(優先的に)閉じることにより防ぎうる合 併症である.

以上，硬膜動静脈㾇の血管内治療に伴う合併症について われわれの経験を報告し，その対策について考察した。

\section{文献}

1) Aihara N, Mase M, Yamada, et al: Deterioration of occular motor dysfunction after transvenous embolization of dural arteriovenous fistula involving the cavernous sinus. Acta Neurochir (Wien) 141: 707-709, 1999

2) Arai K, Nakahara I, Taki W, et al: A case of cavernous dural arteriovenous fistula resulting in intracerebral extravasation during transvenous embolization. No Shinkei Geka 25: 733-738, 1997

3) Deveikis JP: Sequential injections of amobarbital sodium and lidocaine for provocative neurologic testing in the external carotid circulation. AJNR Am J Neuroradiol 17: 1143-1147, 1996

4) Endo S, Kuwayama N, Takaku A, et al: Direct sinus packing of the isolated sinus in patients with dural arteriovenous fistulas of the transverse-sigmoid sinus. J Neurosurg 88: 449-456, 1998

5) Kuwayama N, Endo S, Kitabayashi M, et al: Surgical transvenous embolization of a cortically draining carotid cavernous fistula via a vein of the sylvian fissure. AJNR Am J Neuroradiol 19: 1329-1332, 1998

6）桑山直也，遠藤俊郎：脳神経外科大系，8，出血性脳血管障 害, 硬膜動静脈㾇, 中山書店, 東京, 2004, pp346-359

7) Nagy ZZ, Nemeth J, Suveges I, et al: A case of paradoxical worsening of dural-sinus arteriovenous malformation syndrome after neurosurgery. Eur $J$ Ophthalmol 5: 265-270, 1995 